\title{
Toilet habits in kindergarten children in a kindergarten in Hanoi
}

\author{
Thi Kim Anh Nguyen ${ }^{1,2,3}$, Susan J. Vernon ${ }^{4}$, Ann Bengtson ${ }^{3^{*}}$, Anna-Lena Hellström ${ }^{3,5}$ \\ ${ }^{1}$ Bach Mai Hospital, Hanoi, Vietnam \\ ${ }^{2}$ Hanoi Medical University, Hanoi, Vietnam \\ ${ }^{3}$ Institute of Health and Care Sciences, Sahlgrenska Academy, University of Gothenburg, Gothenburg, Sweden; \\ *Corresponding Author: Ann.B.Bengtson@gmail.com \\ ${ }^{4}$ Department of Clinical Medical Sciences, Great North Children’s Hospital, Newcastle University, Newcastle upon Tyne, UK \\ ${ }^{5}$ Queen Silvia Children’s Hospital, Gothenburg, Sweden
}

Received 30 August 2013; revised 30 September 2013; accepted 15 October 2013

Copyright (C) 2013 Thi Kim Anh Nguyen et al. This is an open access article distributed under the Creative Commons Attribution License, which permits unrestricted use, distribution, and reproduction in any medium, provided the original work is properly cited.

\begin{abstract}
Objective: Describe children's toilet habits in a kindergarten setting. Subjects: Forty-one children aged 4 - 5 years, parents and six teachers participated. Method: Open-ended interviews and observations. Results: In school children avoided going to toilet, this could cause incontinence. Related Factors: Inadequate toilet standards and differing cleaning routines as at home. Children were uncomfortable and shy using the toilet, and some children seemed to prefer playing and school work instead of going to the toilet during breaks. Conclusion: Children of 4 5 years of age are sometimes not able to control their bladder and bowel habits in an environment differing to home.
\end{abstract}

Keywords: Children; Toilet Habits; Interviews; Observations

\section{INTRODUCTION}

Control of bladder and bowel function is important for children in all communities. To be unable to reach common expectations is stressful for both children and parents [1]. According to Vietnamese traditions parents potty train their children from infancy and most children have consistent bladder control about one year of age [2]. Studies in Western countries have shown that children frequently use super-absorbent diapers and obtain control of the urinary bladder and bowels under the age of 3 - 4 years $[3,4]$. Children start kindergarten, in Vietnam about 2 - 3 years of age, which they attend 5 days a week, often for 10 hours.
Previous European studies found that the school toilets are frequently a major problem for children. Many are afraid of visiting school toilets and use various tactics to avoid doing so [5]. Many children do not experience the school toilets as safe or clean [6,7]. In some children avoidance of going to the toilet at school negatively affects health, with possible resultant consequences such as bladder dysfunction, urinary tract infections, constipation and psycho-social problems [4,8-11].

Reason for this study:

Children of kindergarten age are more vulnerable than older children and there are limited studies (worldwide) in this age group regarding school toilets and habits.

\section{PURPOSE}

The purpose was to describe and identify related factors in the toilet habits of kindergarten children in Hanoi.

\section{METHODOLOGY}

\subsection{Setting}

Data collection was from a kindergarten which was highly esteemed and situated in the center of Hanoi. The school has children aged 18 months to 5 years old, the majority are 3 - 5 years old. The total number of children in the school was currently 730, divided into 17 classes with 12 classes (546 children) more than three years old. There were 63 staff in total and each class had 2 teachers, caring for and teaching children, the teachers' were all graduates. The condition of the school building is in need of major restoration, and there are poor toilets. All the problems in this kindergarten are characteristics of many others in Hanoi. 


\subsection{Participants}

Pre-school children, 4 - 5 years of age and their teachers and parents.

\subsection{Ethical Approval and Implications}

Ethical approval was obtained from the Ethic committee at National Pediatric Hospital Hanoi, Vietnam. Participation was voluntary after informed consent. All information about subjects was kept confidentially and data from this study will not be used for other aims. The head of the kindergarten in Hanoi, Vietnam also agreed to this study.

\subsection{Study Design}

The design was a cross sectional study, using a combination of quantitative and qualitative methods.

\subsection{Data Collection Method}

Students (previously taught research methodology) from the nursing department of Hanoi Medical University collected data. Three classes were chosen with children aged 4 - 5 using the strategy of purposeful sampling [12], approval was obtained from the 6 teachers of these classes. In each class there were 49 - 50 children, of whom 15 were randomly selected (total $=45$ children). Letters were sent to the parents, explaining the study and asking for consent for permission to observe their children over 2 days in class. All gave their informed consent

The toilets were inspected (cleanliness, toilet equipment) as well as children's fluid intake. After observation of the children in class, 6 teachers from these classes were interviewed. Finally, parents of the children selected for the observation were interviewed.

Four open ended questions were used for the interviews of the teachers:

- What is your opinion about children's toilet habits in school?

- How does the child manage the toilet procedure (for instance cleaned after he/she urinates or defecates)?

- How do psychological aspects such as shyness, lack of privacy relate to children's toilet habits?

- How do toilet facilities affect children's toilet habits? The corresponding questions to the parents were:

- What are the child's toilet habits at home?

- How does the child manage using the toilet at home, to be cleaned after he/she urinates or defecates?

- How is the toilet like at home?

- What do you and your child think about urinating defecating using class toilet?

Other questions were added during the interview like, "please explain more", "what do you mean" and "is there anything else you would like to tell me”. Most of the interviews of teachers were individual and in the classroom. Interviews for parents were conducted in a separate room in the kindergarten.

All interviews were tape recorded and lasted from 15 25 minutes. However, during the interviews with parents, saturation principle was used [12] to complete data collection, after interviewing 25 people no more new information emerged.

\subsection{Data Analysis}

Data including observation of intake of water, toilet visits and toilet equipment are reported. The interviews have been analyzed using the technique of Krippendorff [13]. This method starts with blind transcription of the interviews. All texts were read several times in order to obtain an overall impression of the meaning of the text as a whole. Meaningful units were identified and condensed. After several processes of coding and decoding, 4 categories were identified and each category includes 2 - 5 sub-categories (Tables 1 and 2). The process of identification of categories included an alteration between the text as a whole and its parts [13]. Describing the analysis in steps ensured trustfulness, quotations are used to support findings. The analysis has been done individually and in cooperation until agreement was reached between the authors.

\section{RESULTS}

\subsection{Observation}

During the study period 4 children were absent of the 45 included; the other 41 children were observed during 2 days (19 boys and 22 girls). There were 6 observers, 2 for each class and 1 per 7 children. The study was performed in the beginning of April, the temperature was between 28 - 30 degrees Celsius.

\subsubsection{Fluid Intake/Water Supply}

Children drank water themselves when they felt thirsty. Each child was offered $150 \mathrm{ml}$ of vegetable soup for lunch and $150 \mathrm{ml}$ of fruit juice for the light meal after the nap. The observers found that during one day 19 of the children did not drink any water in class however in the 2 meals, they had $300 \mathrm{ml}$ including the vegetables soup and fruit juice. Eighteen children drank water 1 - 2 times/ day at class, 4 drank water 3 - 4 times/day at class. The rest drank water from 1 - 4 times in 10 hours in class. Totally each child drank in mean $380 \mathrm{ml}$ water per school day, minimum was $300 \mathrm{ml}$ and maximum is $620 \mathrm{ml}$.

\subsubsection{The Toilet-Activities of Children at School (7. am - 5. pm)}

All children used to urinate at least once and at most 
Table 1. Example of the analytic process, from condensed meaning units of the text, codes, sub-categories and categories.

\begin{tabular}{|c|c|c|c|}
\hline Condensed meaning units & Codes & Sub-categories & Categories \\
\hline $\begin{array}{l}\text { Parents; The child drank (yesterday) both water and milk } \\
\text { about more than } 1000 \mathrm{ml}\end{array}$ & Drink & Drink intakes & $\begin{array}{l}\text { Water supplying } \\
\text { and toilet habits }\end{array}$ \\
\hline $\begin{array}{l}\text { One day when I (mother) took him to the class, he said he } \\
\text { wanted to defecate. I told the teacher he didn't defecate at } \\
\text { home yet so I asked her for attention to the child. But at } \\
\text { the end of the day when I picked him up, the teacher said } \\
\text { he didn't defecate during the school day. He rushed to the } \\
\text { toilet as soon as we came home. When I asked him, he said } \\
\text { he didn't like defecating in class }\end{array}$ & $\begin{array}{l}\text { Does not like defecating } \\
\text { in class toilet }\end{array}$ & Avoiding defecate in school & $\begin{array}{l}\text { Water supplying } \\
\text { and toilet habits }\end{array}$ \\
\hline $\begin{array}{l}\text { Parents; He doesn't like defecating in class because teachers } \\
\text { only use toilet paper. At home he is often washed with } \\
\text { water }\end{array}$ & $\begin{array}{l}\text { Use toilet paper Parents } \\
\text { use water for cleaning }\end{array}$ & $\begin{array}{l}\text { The way to clean } \\
\text { the child in class }\end{array}$ & $\begin{array}{l}\text { Differences in the } \\
\text { way to clean the child } \\
\text { after toilet visits. }\end{array}$ \\
\hline I used to clean my child with water after defecation & Parent use to clean & $\begin{array}{l}\text { The children cannot } \\
\text { manage themselves }\end{array}$ & $\begin{array}{l}\text { Differences in the } \\
\text { way to clean the } \\
\text { child after toilet visits }\end{array}$ \\
\hline $\begin{array}{l}\text { Teachers: Toilets are under-standard, about } 100 \text { children } \\
\text { share one toilet, it is too dense and not always clean } \\
\text { because of water lacking, and warm water must be fetched } \\
\text { from far away }\end{array}$ & Under standard toilets & $\begin{array}{l}\text { Standards of toilet } \\
\text { Too many children } \\
\text { Standards of toilet }\end{array}$ & Toilet problems in class \\
\hline $\begin{array}{l}\text { Two teachers for each class have too much work. When } \\
\text { they do not pour water afterwards, it smells bad }\end{array}$ & Too much work & Too many children & Toilet problems in class \\
\hline $\begin{array}{l}\text { Children can't go to the toilet during lessons because there } \\
\text { is a fact that when one child goes there, others will imitate } \\
\text { and ask for permission to go there too }\end{array}$ & $\begin{array}{l}\text { Can't go to the toilet } \\
\text { during lessons }\end{array}$ & Toilet regulations & Toilet problems in class \\
\hline $\begin{array}{l}\text { The current toilets included unsuitable sizes and equipment } \\
\text { so the teachers even trying their best could not make the } \\
\text { toilet away from bad smell }\end{array}$ & $\begin{array}{l}\text { Unsuitable sizes } \\
\text { and equipment }\end{array}$ & Standards of toilet & Toilet problem in class \\
\hline Parents: We train toilet habit before going to kindergarten & Training toilet habit & $\begin{array}{l}\text { Age of training toilet habit } \\
\text { before going to kindergarten }\end{array}$ & $\begin{array}{l}\text { Parent's concern about } \\
\text { toilet habit of children }\end{array}$ \\
\hline $\begin{array}{l}\text { My child used to have dark yellow urine when she came } \\
\text { back home, I think she did not drink enough water. I gave } \\
\text { her water and then in the evening she had clear urine }\end{array}$ & $\begin{array}{l}\text { The change of } \\
\text { urine color }\end{array}$ & $\begin{array}{l}\text { Parent's concern about } \\
\text { health of their children }\end{array}$ & $\begin{array}{l}\text { Parent's concern about } \\
\text { toilet habit of children }\end{array}$ \\
\hline
\end{tabular}

Table 2. Categories and sub-categories.

\section{Categories}

Water supplying and toilet habits

\section{Sub-categories}

Avoiding defecate/urinate/postpone in school

Frequent urinations at home

Reminding

Enuresis/constipation/incontinence

Differences in the way to clean the child after toilet visit

Toilet problems in class
The way to clean the child

Children cannot manage

Standard of toilets

Too many children

Toilet regulations

Uncomfortable feeling

Age of training toilet habit is before going to kindergarten
Parent's concern about toilet habit of children

Parent's concern about health of their children 
six times during the school (Table 3) but they never used the toilet for defecating during the study period. In addition, there were 5/41 children who were incontinent (2 had episodes during playing time, and 3 during the sleep).

\subsubsection{Toilet Equipment}

In the 3 classes that were studied, two of them had separate toilets for the class which were comprised of separate areas for urination and defecation; however the same room was shared by girls and boys. Each toilet room had 2 opposite sites for defecating with squatting toilet constructed for adult use, and 2 lines for urinating (one side for boys to standing when urinating and the opposite side for girls to squatting when urinating), and one hand basin for hand washing. Four children could urinate at the same time, and after that the teachers poured water down the toilet. All water used for cleaning must be brought and used by the teachers. The third class observed had to share toilets with another class (who were not included in the study). This toilet had 2 sites for defecating: lavatory toilet and 2 lines for urinating like the one mentioned above. None of the toilet rooms had warm running water available for hand washing. Towels, soap, toilet paper were not always available (only 3 - 4 pieces of towel for the whole class which were often dirty and damp), the floor was sometimes wet, and all toilets had a unpleasant smell.

\subsection{Interviews with Teachers and Parents}

The findings are presented below in the 4 categories emerged during the analysis.

\subsubsection{Water Supplying and Toilet Habits}

Fluid intake is closely related to toilet habits and in this study we found that children drank less water in school than at home. The children were offered water to drink at school but it was impossible for the teachers to know how much they drank. The teachers were aware of the fact that children could forget to drink whilst they were playing. At home they drank more frequently, parents estimated from $800 \mathrm{ml}$ up to $2000 \mathrm{ml}$ included boiled water, milk, fruit juice and vegetable soup. At home most children went to the toilet when they wanted,

Table 3. The number of times children urinate during the 10 hours in school.

\begin{tabular}{cc}
\hline Number of urinating times & Number of children (\%) \\
\hline $1-2$ times & $15(36.6)$ \\
$3-4$ times & $16(39.0)$ \\
$>4$ times & $10(24.4)$ \\
\hline
\end{tabular}

their parents could not remember exactly how many times. However they knew the certain times were, morning when they woke up, at night before going to bed (parents often reminded children to go to the toilet as the teachers did).

All the teachers said that most of the children had developed good toilet habits but need be reminded to use the toilet at suitable times. The routines were break for toilet visits for all children before morning exercise, before lunch time, before sleep at noon, after sleep and before going home.

Whilst postponing going to the toilet was common in school, it could also happen at home. This habit was observed by some parents when their child was playing, and in school it was obvious when they avoided using the toilet. "My girl is so occupied in playing (at home), so she flexes the legs and she can go on so and playing for hours", another parent said "Once I took him to the class, he told me he wanted to defecate. I asked the teacher to pay attention to him during the day. But at the end of the day when I picked him up the teacher said he didn't defecate. When we arrived home he hurriedly rushed into the toilet”. Most children also needed help from the teacher to clean themselves afterwards which made them embarrassed Teacher: "In general, children prefer defecating at home because there they can feel more comfortable with flat latrine”.

The teachers stated that some children (17/149) 11\% suffered from incontinence in class. Some were incontinent of urine and faeces, causing problems for themselves as well as affecting their friends. If this happened during the nap, their friends might become wet if the teacher did not detect this immediately. If this happened during lessons, the lesson would be interrupted. "The teacher didn't know about it until his classmates told there was a bad smell". The teachers assumed that these children were unhappy about being incontinent however no bullying was observed. The teachers also tried to observe that these children really went to the toilet at the certain times. "Some children refuse to go to the toilet when I remind. When I asked, he said that he had already been to the toilet but in fact he hadn't. So, when I took him to the toilet, he produced much urine and at that naptime he did not have enuresis".

Incontinence episodes were rare when at home "Anyway going to the toilet at home is more comfortable, and the same can be with adults". The parents knew that their children could have this problem in school. "My child didn't use to have enuresis but since he came to kindergarten, the frequency has increased". However, parents described recent episodes of incontinence during the potty training process. Two of them had had to use diapers at night. The rest had never used diapers.

Since starting kindergarten the child's habit of defe- 
cating when they felt they need to had changed. Before the children started kindergarten, they were often in the habit of defecating in the morning. But since they attended kindergarten the habit had changed to afternoon. Some parents expressed that they wanted their children to get in the habit of poo-ing in the morning but they could not always achieve this. In some ways this was convenient for the family because the evenings were not so rushed. However, this postponement caused problems for the children, because they postponed their need to defecate for the whole day. "My child used to poo in the morning but when he started kindergarten, it was such a hurry in the morning and he was afraid of the teacher so he postponed all day. His habit has moved to the evening".

Some children (7/25) defecated in the morning before they went to kindergarten, these children could play all day comfortably, and parents did not worry about this. In reality training the children to poo in the morning was not easy because children often woke up late and parents had to hurry to work. "When my little girl sits on the potty, she has breakfast, she has her teeth brushed, her face cleaned because she gets up late. She often goes to bed at 11 or 12 p.m. so she cannot get up early. Everything is in a hurry. In addition, our family's intention is that our girl should not poo when in school".

\subsubsection{Differences in the Way Children Are Cleaned after Toilet Visits}

Routines for cleaning after using the toilet were not the same in school as at home. In school, toilet paper was used only after defecation. After defecation, teachers used to clean the child with toilet paper and used water only when the child was incontinent. This contrasted with parents expectations, they expressed after defecating children should be cleaned with water and soap so they could feel comfortable and clean, at home most parents did this for their children. Few parents said they only used paper to clean, and a reason for this was that the children defecated in the late afternoon and they used to have a bath in the evenings. Another one told " $M y$ child is special, after defecation he only accepts water cleaning, unhappily if there is no water at home, I will beg from my neighbors. If not, he refuses to get dressed again". The difference in routines could cause problems for the children "When I asked my girl, she said the toilet in class was not nice, she didn't like defecating in class because there the teachers used paper only, and she didn't like that. At home she was familiar with being cleaned with water. She also said that it was not clean just to use paper”.

Many parents worried that their children could not manage by themselves, and it became clear that the children had not been trained to clean themselves. At home girls had been told how to use toilet paper or soft cloth after urination, but some mothers helped their children to clean with water immediately after the children urinated. "When my daughter comes back home, her genital smells so terrible because in class no one had cleaned her. When we come home, the first I do is to clean her and change clothes".

\subsubsection{Toilet Problem in Class}

This study showed the physical standard of toilets were poor. One teacher expressed that there was no warm water for hand washing, and toilets were not always clean because of lack of water. Due to the limited availability of water children were not encouraged or able to wash their hands "The school should have large and clean toilets without bad smell for children, inside there should be attractive decorations so that children can enjoy going to toilets. There should be warm water in order to bring convenience to the cleaning for children".

Sometimes the toilets smelt unpleasant because the teachers were not able to pour water down the drain after use (equivalent to flushing the toilet). This was due to a combination of lack of water and time. The teachers found the situation unsatisfactory.

Children felt pain when squatting-teachers reported "Some complain that they have numb feet after defecating". "The current toilets included unsuitable sizes and equipment so the teachers even trying their best could not make the toilet away from bad smell and moreover, children are too many, 50 children per class, and there are two teachers for all". One mother said that her little girl frequently wet her pants "Because she could not stand the terrible smell in the class toilet”. Parents said that their families used potties at home (because the toilet was too high) for the child to let them sit comfortably. At home, toilets were described by the parents, as always being clean and equipped with toilet paper, soap, hand cleaning water, towel and especially warm water in the winter.

Teachers had observed some children had constipation and that a few children had signs of a sharp and burning pain when urinating. These parents were advised to see a doctor. More than half of parents said sometimes their children had suffered from constipation. It was often happened with a few children — a parent said "My child sometimes has constipation and spends hours on the pot, every time he cries, I am so frightened".

When discussing toilet regulations the teachers said that children often disobeyed the teacher by not taking responsibility for their need. During the regular breaks for toilet visits some children did not like to go at the same time as everybody else. The children were reminded that using the toilet during lessons was not appropriate. "Sometime I reminded them, you can't go to 
the toilet during lessons. Maybe because of this, children do not dare to ask for permission to go to the toilet. And this is also the children's responsibility". The teachers used to tell parents during class meetings that they should get their children to defecate in the mornings before coming to kindergarten. "I remind them so that they have a habit because at home it is clean and warm water". This advice was to prevent the children defecating during the school day. Another teacher stated that there was written in the regulations that children could not go to the toilet during lessons. "Children can't go to the toilet during lessons because when one child goes there, others will imitate and ask for permission to go there too".

When parents' ideas were taken into consideration, most parents expressed that the school toilet and the child's feeling of comfort influenced toilet habits; at home they always felt comfortable but this was not always the case at school. Apart from hygiene there were some children who felt frightened visiting the class toilet. "My child said sitting there was not as easy as using a pot. Once she wetted the pants, and sometimes she abstained to urinate in class and when her sister picks her up to home, she hurriedly asked to go to a toilet outside". However, it seemed to be easier to express avoidance because of poor hygiene in the toilets than for more personal reasons. Some parents said that it appeared that there were multifactorial reasons for this, children mentioned they did not like to urinate at the same time as the opposite sex, that the appearance of strangers made them embarrassed and hesitant to go to the toilet at school. Others said that children often felt distrusted and under suspicion of doing something else when in the toilet. "My son told me that after visiting the toilet the teacher often asked if he played with water?" Many children told their parents they were afraid and shy of their teachers and did not dare asking permission to go to the toilet "Once a boy was naughty and the teacher shouted to him, then my daughter wanted to urinate but she was so afraid of the teacher, she didn't dare to ask for permission so she wetted her pants".

\subsubsection{Parent's Concerns about Their Children's Toilet Habits at School}

Most parents trained their children to be able go to the toilet at suitable times during the day. They believed this was important to prevent gastro/urinary tract infections and constipation. When their children had established a good routine they felt comfortable and pleasant all day. Parents used to remind their children to go to the school toilet because they were afraid that they would become incontinent at school with resultant embarrassment"Once a child had incontinence, the teacher said there were too many children to help. He could not abstain so he defecated in his pants".

However parents were concerned about the bad state of the class toilets and how this could influence children's health. "I can feel the bad smell when I stand outside, the children can feel too, but they still have to go inside when they cannot postpone any longer". Another parent said that "If there were lavatory pans in class I would feel more secure because it would be firmer". Parents also expressed worries about the possibility of their child becoming ill, because of incontinence and their children's decision not to use school toilets. "The first time he was incontinent regularly. Then, I remind him that incontinence can give kidney problems, since then he hasn't resisted urination". They hoped that if they emphasized the risks of avoiding school toilets their children could think that going to the toilet was important for good health. The parents sometimes used observation of the child's toilet habits as a means of detecting deterioration in health, and they wanted meetings with the kindergarten staff to discuss children's health.

\section{DISCUSSION}

Children in Vietnam are often potty trained from early infancy and achieved independent bladder control around ages 18 months to 2 years of age at home [2]. It is known from earlier studies that school toilets often cause problems for children $[6,7,14]$. This study was aimed to describe the toilet habits in a pre school setting of children and factors influencing these.

In Vietnam there are regulations regarding the condition of school toilets in city kindergartens toilet should be as large as $20 \mathrm{~m}^{2}$ for each class ( 25 - 30 children), the sanitary blocks divided into two separate parts for boys and girls. Each toilet area should have four seats for urination, two lavatory pans, one cistern of water, one hand basin together with one bathroom or shower suitable for pre-school children. They should be clean water and soap available; Regulation about hygienic school-Ministry of Health, 2000; Hygienic standard for all types of toilets —Ministry of Health, 2005 [15,16]. These documents seem to be regarded more like recommendations then regulations, and compete with different priorities in the school environment. School teachers suggested that this was not an optimal situation.

A limitation of this study could be that data collection was carried out in only one large kindergarten. Our topic was sensitive, people usually do not talk about this, and therefore ideas from parents may not absolutely reflect what they really thought. A further limitation was that we did not ask children directly because we did not think that children themselves could give a holistic view of their toilet habits at school. The observation combined with interviews of parents and teachers gave a suitable alternative. 
The lack of class toilets meeting children's requirements (dirty and insufficient toilets) has been cited by previous researchers $[6,7,14]$. Toilet facilities in this kindergarten did not reach the standard recommended by Vietnamese regulations. A bad smell of urine, no water to clean toilets, insufficient toilets and limited privacy meant children were unable to be comfortable to urinate or defecate in the relaxed manner necessary. This differed from what the children were used to from home. This bad standard was regarded as a big problem by everyone involved, children, teachers and parents were concerned that facilities to encourage good toilet habits in kindergarten were lacking.

Fluid intake determines urination [17], daily maintenance fluid requirements for children at this age (mean $15 \mathrm{~kg}$ of weight) are at least $1250 \mathrm{ml}$ per day (including food). This study was performed during spring when the temperature was around 20 - 25 degrees Celsius, loss by sweating is estimated as normal. The children's intake was $1 / 3$ of the total recommended intake during 10 hours in class. Fifteen children had only urinated once or twice during 10 hours in class (which may be because of they did not drink as much). Some children may have forgotten because they were playing or were not reminded by their teachers to drink during breaks. Conversely the children were encouraged to drink in excess of 1000 $\mathrm{ml} / \mathrm{study}$ day (including milk, fruit juice, and boiled water) when they were at home.

The teachers reminded children at predetermined times to go to the toilet. Going to the toilet whilst in class was regarded by the teacher as disturbing the teaching and could only be allowed in an emergency. The teachers stated that because of the large number of children, they only encouraged the children to use the toilet during the toilet breaks. To encourage kindergarten children to go to the toilet at certain breaks supports good habits, however not be able to help the children go to toilet when they feel a need to may cause episodes of incontinence.

Frequently children postponed going to the toilet, possibly due to the poor state of the toilets perhaps because they preferred playing. However, most children around the ages of 4 are not able to postpone going to the toilet for hours with the result that after a while the need to void appears very strong. This might be the reason for some children's incontinence during lessons.

The differences in routines in cleaning compared to home made the children uncomfortable and shy. This study showed that children did not feel as comfortable using kindergarten toilets as they did at home. Other factors in school toilets made children frightened, and they were also uncertain about the teacher's opinion. Children perceptions about differences between boys and girls are very strong [17], and they may feel uncomfortable when sharing toilets. Findings from this study reflected that the children did not appreciate rules governing use of toilets or teacher's reminding them when to go to the toilet. This lead to postponement of toilet visits and possibly sharp, burning pain when urinating mentioned in this study. This is in concordance with some previous studies stressing the risk that avoiding urinate may lead to an increased risk of UTI $[18,19]$.

\section{CONCLUSIONS}

A lot of children urinated infrequently during school time. Many postponed going to the toilet in class, despite official breaks to go to the toilet, many were incontinent during lessons and nap when they had been reliably dry at home.

The reason that children do not use the school toilets during the school day may be multifactorial: toilets were of a low standard; were dirty and smelt unpleasant. There were no separate toilets for boys and girls. Children's need for privacy during toilet visits was not accorded to. The children may have been afraid to ask to go to the toilet because they knew the teachers' opinions about going during class. Teachers were not able to assist in cleaning after using the toilet in the same way children were used to at home. Some children postponed going to the toilet because they were occupied in playing or school work.

\section{Implications}

In kindergarten children need differing support from parents or other adults, to remind them when it is time to go to the toilet, particularly in new and differing situations. They also need adequate support to deal with new situations. Prior visits to school should inform teacher's awareness of individual children's needs, and parents could help children to be independent prior to going to kindergarten. In order to gap the transition to going to a kindergarten there needs to be a full discussion between parents, children and teachers. Toilet breaks in kindergartens are essential to maintain good toilet habits, and whenever a child needs to go one teacher should be available to support the child. This would assist the acquisition of good toilet habit at early age to prevent urinary and bowel problems according to WHO 1997 report Promoting Health by school [20]. Financial support is needed for improvement and repairs for school toilets, to enable kindergartens can reach acceptable standards in accordance Regulations of Ministry of Health.

\section{ACKNOWLEDGEMENTS}

We would like to thank the teachers, children and their parents of the kindergarten who took part in this study.

\section{REFERENCES}

[1] Hägglöf, B., Andrén, O., Bergström, E., et al. (1998) 
Self-esteem in children with nocturnal enuresis and urinary incontinence: Improvement of self-esteem after treatment. European Urology, 33, 9-19.

[2] Duong, H.T., Jansson, U.B., Holmdahl, G., et al. (2010) Development of bladder control in the first year of life in children who are potty trained early. Journal of Pediatric Urology, 6, 501-505. http://dx.doi.org/10.1016/j.jpurol.2009.11.002

[3] Jansson, U.B., Hanson, M., Sillen, U., et al. (2005) Voiding pattern and acquisition of bladder control from birth to age 6 years-A longitudinal study. Journal of Urology, 174, 289-293. http://dx.doi.org/10.1097/01.ju.0000161216.45653.e3

[4] Bloom, D.A., Seeley, W.W., Ritchey, M.L., et al. (2003) Toilet habits and continence in children: An opportunity sampling in search of normal parameters. Journal of Urology, 1499, 1087-1090.

[5] Lundblad, B., Berg, M. and Hellstrom, A.L. (2006) Experiences of children treating functional bladder disturbances on schooldays. Journal of Pediatric Urology, 5, 1-5.

[6] Lundblad, B. and Hellstrom, A.L. (2005) Perceptions of school toilets as cause for irregular toilet habits among school aged 6 to 16 years. Journal of School Health, 75, 125-128.

[7] Vernon, S., Lundblad, B. and Hellstrom, A.L. (2003) Children's experiences of school toilets present a risk to their physical and psychological health. Care, Health \& Development, 29, 47-53. http://dx.doi.org/10.1046/j.1365-2214.2003.00310.x

[8] Loening-Bauke, V. (1997) Urinary incontinence in children and urinary tract infection and their resolution with treatment of chronic constipation of childhood. Pediatrics, 100, 228-232. http://dx.doi.org/10.1542/peds.100.2.228

[9] Hansen, A., Hansen, B. and Dahm, T.L. (1997) Urinary tract infection, day wetting and other voiding symptoms in seven-to eight-year-old Danish children. Acta Pediatric, 86, 1345-1349. http://dx.doi.org/10.1111/j.1651-2227.1997.tb14911.x
[10] Wan, J., Kaplinsky, R. and Greenfield, S. (1995) Toilet habits of children evaluated for urinary tract infection. Journal of Urology, 154, 797-799.

[11] Hansson, S. (1992) Urinary incontinence in children and associated problems. Scandinavian Journal of Urology and Nephrology, 141, 47-55.

[12] Patton, M.Q. (2002) Qualitative research and evaluation methods. 3 rd Edition, Sage, USA.

[13] Krippendorff, K. (2004) Content analysis: An introduction to its methodology. Thousand Oaks, Sage, USA.

[14] Cooper, C.S., Chadi, T., Abousally, J., et al. (2003) Do public teach voiding dysfunction? Journal of Urology, 170, 956-958.

http://dx.doi.org/10.1097/01.ju.0000075916.55446.ee

[15] Regulation about hygienic school-Ministry of health of Vietnam. (2000)

http://www.quangnam.edu.vn/images\%5Cstories\%5Cvan bankhac/qd1221-2000-byt.doc

[16] Hygienic situation in the world. http://vi.wikipedia.org/wiki/Nh\%C3\%A0_v\%E1\%BB\%8 7_sinh\#cite_note-0

[17] Hockenberry, M.J. (2005) Wong's essentials of pediatric nursing. 7th Edition, Mosby Inc., St. Louis.

[18] Wennegren, H.M., Oberg, B.E. and Sandstedt, P. (1991) The importance of leg support for relaxation of the pelvic floor muscles. Scandinavian Journal of Urology, 25, 205213. http://dx.doi.org/10.3109/00365599109107948

[19] Moore, K.H., Richmond, D.H., Sutherst, J.R., et al. (1991) Crouching over the toilet seat: Prevalence among British gynaecological outpatients and its effect upon micturition. An International Journal of Obstetrics \& Gynaecology, 98, 569-572. http://dx.doi.org/10.1111/j.1471-0528.1991.tb10372.x

[20] World Health Organisation (1997) Promoting health through schools. Report of a WHO Expert Committee on Comprehensive School Health Education and Promotion. World Health Organisation, Geneva. 